\title{
Gas Phase Hydrogen / Deuterium Exchange in Electrospray Ionization Mass Spectrometry as a Practical Tool for Structure Elucidation
}

\author{
Mark E. Hemling, James J. Conboy, Mark F. Bean, Mary Mentzer, and \\ Steven A. Carr \\ Physical and Structural Chemistry, SmithKline Beecham Pharmaceuticals, King of Prussia, Pennsylvania, USA
}

\begin{abstract}
Two methods for gas phase hydrogen/deuterium exchange have been developed for the analysis of small molecules. Hydrogen/deuterium exchange has been implemented by making simple modifications to the plumbing for the nebulizer and curtain gases on a nebulization-assisted electrospray ion source. The nebulizer gas exchange method has demonstrated deuterium exchange levels of $84-97 \%$ for a variety of molecules representing a wide range of structural classes containing up to 51 potentially exchangeable hydrogens; this allowed determination of the number of exchangeable hydrogens for all of the molecules studied containing $\leq 25$ labile hydrogens $\left(M_{1} \leq 3000\right)$. $\mathrm{ND}_{3}$ gas consumption is minimized in the nebulizer method by toggling the nebulizer from air to $\mathrm{ND}_{3}$ for only a few scans of the total sample elution period. The curtain gas exchange method is more variable, yielding exchange levels of $32-98 \%$ for the same set of molecules; this was still sufficient to allow determination of $>70 \%$ of the molecules studied containing $\leq 25$ labile hydrogens. Gas consumption is minimized in the curtain method by replacing $\leq 10 \%$ of the curtain gas flow with $\mathrm{ND}_{3}$. Neither the nebulizer nor curtain exchange method requires the use of deuterated or aprotic solvents at typical $2 \mu \mathrm{L} / \mathrm{min}$ flow rates. (I Am Soc Mass Spectrom 1994, 5, 434-442)
\end{abstract}

$\mathrm{T}$ The measurement of the number of active hydrogens in a molecule by various types of hydrogen/deuterium $(\mathrm{H} / \mathrm{D})$ exchange experiments is a useful adjunct to several analytical techniques, including nuclear magnetic resonance and mass spectrometry. These measurements have been an aid in the elucidation of compounds of unknown structure, in the determination of mechanisms of chemical and biological reactions, and in interpretation of fragmentation pathways in mass spectra $[1,2]$. Various means for making such measurements have been developed for nearly every ionization/sample introduction method that has been widely used including electron ionization (EI) [3], chemical ionization (CI) [4], fast-atom bombardment (FAB) [5], thermospray [6, 7], particle beam [8], matrix-assisted laser desorption ionization [9], gas chromatography mass spectrometry [10], and liquid chromatography/mass spectrometry (LC/MS) [11]. Recent work in the analysis of protein conformation by electrospray ionization mass spectrometry (ESIMS) has made use of both solution phase and gas phase (atmospheric pressure or in vacuo) hydrogen/ deuterium exchange methods. The solution phase exchange often requires special efforts such as flooding

Address reprint requests to Mark E. Hemling or Steven A. Carr, Physical and Structural Chemistry UW2940, SmithKline Beecham Pharmaceuticals, P.O. Box 1539, King of Prussia, PA 19406-0939. the atmospheric pressure source region with dry air in order to reduce back exchange [12]. The gas phase protein exchange experiments required the long residence times of a Fourier transform ion cyclotron resonance instrument to generate a sufficient number of collisions for reasonable levels of exchange [13] or required a heated dual-capillary inlet reactor interface for desolvation and then exchange of the sample molecules [14].

Here we describe two methods for gas phase hydrogen/deuterium exchange which require only simple changes to the plumbing of our nebulization-assisted electrospray ion source. Effective exchange of active hydrogens is achieved by replacing either all of the nebulizer gas or part of the curtain gas with a deuterated exchange agent such as $\mathrm{ND}_{3}$. These methods provide for essentially complete exchange of all active hydrogens on many of the types of small molecules (e.g., alkaloids, glycosides, etc.) for which H/D exchange has been of proven utility in structure elucidation work. The number of exchangeable hydrogens for larger molecules containing up to 25 exchangeable hydrogens (including peptides) could be determined by these methods, although exchange may be incomplete. These methods work without the requirement of dissolving the sample in deuterated or aprotic solvents, although deuterated solvents and the avoidance of high flow rates of protic solvents can be beneficial in 
the analysis of refractory molecules. A simple ESIMS $H / D$ exchange experiment is a useful addition to the mass spectrometrist's armamentarium for the elucidation of unknown structures. With these new methods, $\mathrm{H} / \mathrm{D}$ exchange is now extended to classes of compounds not amenable to FAB or direct chemical ionization (DCI), especially in cases where sample amounts are limited.

\section{Experimental}

\section{Materials}

All components used in the modifications to the interface plumbing were selected to be compatible with $\mathrm{ND}_{3}$, for example, stainless steel, indium (interface region vacuum seals), Teflon, and glass as described below. $\mathrm{ND}_{3}(99+\%$, Isotec, Miamisburg, $\mathrm{OH}$; or $99 \%$, Cambridge Isotopes, Woburn, MA) was analyzed by $\mathrm{DCI}$ for $\% \mathrm{D}$ prior to use by measuring the $\mathrm{ND}_{4} / \mathrm{NHD}_{3}$ ratio on the ammonium adduct ion of a standard such as methyl stearate. Compounds used in this work were purchased from commercial sources and used without further purification: norphenylephrine $\cdot \mathrm{HCl}$, riboflavin, oxidized insulin B chain (Aldrich Chemical Co., Milwaukee, WI); ascorbic acid (J. T. Baker, Phillipsburg, NJ); methionyl-leucyl-phenylalanine • HOAc (Sigma Chemical Co., St. Louis, MO); threonyltyrosyl-seryl-lysine (Vega Biotechnologies, Inc., Tucson, AZ); renin substrate-(1-14) (Peninsula Laboratories, Belmont, CA); sucrose, raffinose, stachyose, maltopentaose (Pfanstiehl Labs, Waukegan, IL); digitonin (A grade; Calbiochem, Los Angeles, CA); $(\mathrm{dTp})_{7} \mathrm{dT}$, (dTp) ${ }_{19} \mathrm{dT}$ (Comell Biotechnology Program Oligonucleotide Synthesis Facility, Ithaca, NY); holothurin B [15] was isolated at SmithKline Beecham from natural sources. Solvents and buffers used were of the highest purity available.

\section{Instrumentation}

A Sciex API-III triple quadrupole system was modified for $\mathrm{ND}_{3}$ introduction in either the nebulizer or curtain regions as shown in Figure 1. To permit nebulizer exchange, the lecture bottle containing $\mathrm{ND}_{3}$ (a) was connected via $1 / 8$ in. i.d. stainless steel (s.s.) tubing to a Teflon/glass flow meter (b) (P/N T54/6-052-01, Scientific Instrument Services, Ringoes, NJ), and then via $1 / 8$ in. i.d. Teflon tubing to a three-way s.s. valve (c) (P/N SS-41XS2, Whitey Co., Highland Heights, $\mathrm{OH}$ ), placed in the zero air gas line $(\mathrm{g})$ used for nebulization. To permit exchange experiments in the curtain region, the $\mathrm{ND}_{3}$ bottle (a) was also connected by a s.s. tee via s.s. tubing to a flow controller with a fine metering valve (d) ( $P / N$ T51/1-062-01, Scientific Instrument Services, Ringoes, NJ), through a s.s. diaphragm valve (e) (P/N SS-DL-S4, Nupro Co., Willoughby, OH) for vacuum isolation, and teed into the ultra high purity nitrogen curtain gas line (f) supplied with the instru-

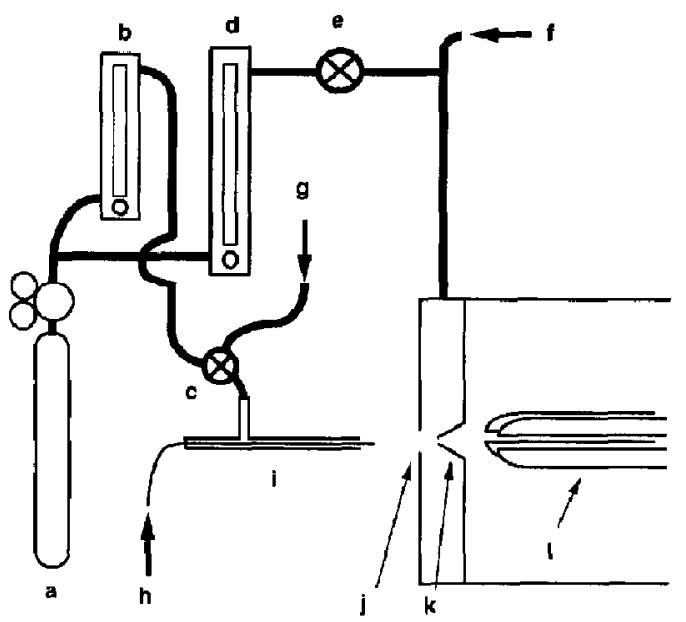

Figure 1. Modification of nebulizer and curtain gas plumbing on Sciex API III nebulization-assisted electrospray source: (a) $\mathrm{ND}_{3}$ cylinder; (b) flowmeter; (c) three-way valve; (d) flowmeter; (e) vacuum isolation valve; (f) ultrahigh purity $\mathrm{N}_{2}$ curtain gas; (g) zero air nebulizer gas; (h) fused silica solvent line; (i) ion spray nebulizer; (j) interface plate; $(\mathbf{k})$ ion-sampling skimmer orifice; (1) RF-only quadrupole, $\mathrm{Q}_{0}$.

ment. The Teflon gasket/Viton O-ring vacuum seal between the interface plate $(j)$ and orifice plate $(k)$ was replaced with an older version Macor gasket/indium wire seal to minimize $\mathrm{ND}_{3}$ absorption during the curtain gas exchange experiments. During nebulizer exchange valve (e) is closed and valve (c) is used to select either $\mathrm{ND}_{3}$ or zero grade air $(<0.1 \mathrm{ppm}$ hydrocarbon; model 75-85 Zero Air Generator, Balston, Haverhill, MA) for nebulization. For curtain exchange, valve (c) is set to select zero grade air for the nebulizer, and valve (e) is open to allow $\mathrm{ND}_{3}$ into the curtain gas. The interface region is vented by an exhaust fan to prevent $\mathrm{ND}_{3}$ (and aspirated solvents, samples, etc.) from contaminating the laboratory atmosphere. Samples $(2-3 \mu \mathrm{L}$, dissolved in the elution solvent) were introduced by loop injection and infused (h) into the ion spray interface (i) at $2-3 \mu \mathrm{L} / \mathrm{min}$. The potential difference between the orifice (OR) and DC-offset (RO) of the RF-only quadrupole (1) of the ion sampling region is referred to as the declustering potential. DCI $\mathrm{H} / \mathrm{D}$ exchange experiments were performed on a Fisons VG 70-VSE mass spectrometer with either a standard EI $/ \mathrm{CI}$ or CI-only source using normal $\mathrm{NH}_{3}-\mathrm{CI}$ conditions. $\mathrm{FAB} \mathrm{H} / \mathrm{D}$ exchange experiments were performed on a Fisons VG ZAB-SE4F mass spectrometer with either a standard $F A B$ source or a continuous flow FAB source operated in the normal FAB mode; $\sim 35 \mathrm{kV} \mathrm{Cs}^{+}$ions were used for bombardment.

\section{Methods}

Nebulizer Exchange. Samples were dissolved in elution solvent $\left(50 / 50 \mathrm{CH}_{3} \mathrm{OH} / \mathrm{H}_{2} \mathrm{O}\right.$ with $0.2 \% \cdot \mathrm{HCOOH}$; 
or $50 / 50 \mathrm{CH}_{3} \mathrm{CN} / \mathrm{H}_{2} \mathrm{O}, 95 / 5 \mathrm{CH}_{3} \mathrm{CN} / \mathrm{H}_{2} \mathrm{O}$, or $90 / 10$ $\mathrm{CHCl}_{3} / \mathrm{CH}_{3} \mathrm{OH}$ with $5 \mathrm{mM} \mathrm{NH} \mathrm{OACl}_{4}$ and introduced by loop injection (2-3 $\mu \mathrm{L} / \mathrm{min}$ unless noted otherwise) into the ion spray interface. Nebulizer gas $(\sim 0.7$ $\mathrm{L} / \mathrm{min})$ was toggled from zero air $(30-35 \mathrm{psi})$ to $\mathrm{ND}_{3}$ (29-30 psi) after the signal maximized and then back to zero air after $\sim 10$ scans ( $\leq \sim 1 \mathrm{~min}$ ) using valve (c), Figure 1. For combined solution and nebulizer gas phase exchange of renin substrate-(1-14), the sample was dissolved in 2:3:3 $\mathrm{d}_{4}$-acetic acid/d $/ \mathrm{d}_{4}$-methanol/ $\mathrm{d}_{2}$-water and flow injected into $1: 1 \mathrm{~d}_{4}$-methanol/ $\mathrm{d}_{2}$ water flowing at $3 \mu \mathrm{L} / \mathrm{min}$; the atmospheric pressure ionization region was purged with dry $\mathrm{N}_{2}$.

Curtain Exchange. Samples were introduced as described above. $\mathrm{ND}_{3}$ exchange gas was added to the $\mathrm{N}_{2}$ curtain by a flow controller $(1-10 \%$ curtain flow) with simultaneous increase of the declustering potential $(\mathrm{OR}-\mathrm{RO}=120-220 \mathrm{~V})$ to reduce $\mathrm{ND}_{3}$ clustering and adduction and to increase the extent of exchange. Residual $\mathrm{ND}_{3}$ gas was removed completely only after a recycle of the cryopumping system, which is routinely recycled during a $10 \mathrm{~h}$ period ovemight.

$D C I$ and $F A B$ Exchange. $D C I H / D$ exchange was performed identically to a normal $\mathrm{NH}_{3}-\mathrm{DCl}$ experiment except that $\mathrm{ND}_{3}$ was used as the reagent gas. $\mathrm{FAB}$ $H / D$ exchange was performed by repetitively $(3 \times)$ dissolving the sample in deuterated solvent (MeOD or AcOD $/ \mathrm{D}_{2} \mathrm{O}$ ) followed by drying under dry argon or in vacuo and then analyzing the redissolved sample in previously exchanged thioglycerol matrix.

\section{Results and Discussion}

Our initial experiences with hydrogen/deuterium exchange in solution pointed to the need to carefully control such parameters as the quality of the deuterated solvents and the moisture content of the atmosphere in the source region which may have resulted in back exchange [12]. Coupled with the desire to be able to generate $\mathrm{H} / \mathrm{D}$ exchange data quickly and easily, a modification was made to the plumbing of our Sciex API-III electrospray source to investigate gas phase $H / D$ exchange in the nebulization/ionization region or in the curtain / free-jet expansion region. This modification (Figure 1) involved (1) the addition of a valve prior to the nebulizer to allow for rapid switching from the zero grade air normally used for nebulization to $\mathrm{ND}_{3}$ and (2) the addition of a valve and tee to the curtain gas line to allow for the addition of $\mathrm{ND}_{3}$ to the $N_{2}$ curtain gas. Neither of these modifications interferes in any way with the normal operation of the instrument. While nebulizer $H / D$ exchange was presumed to be the easiest method for achieving exchange, the curtain exchange method was also investigated in the belief that potential back exchange would be avoided and that more effective collisions in this region would result in a higher degree of exchange with less $\mathrm{ND}_{3}$ consumed.

\section{Nebulizer Exchange}

During flow injection analysis of a sample, $H / D$ exchange is readily affected by rapidly switching the nebulizer flow from air to $\mathrm{ND}_{3}$ for several scans, then switching back to air, thereby providing both normal and exchanged data in a single experiment. This often leads to noticeable suppression of desorption/ionization in the positive ion mode or enhancement in the negative ion mode (Figure 2) which can be useful for selecting scans for analysis. These suppression/ enhancement effects may be due to dissolution of the $\mathrm{ND}_{3}$ in the evaporating electrospray droplets causing a change in $\mathrm{pH}$ and thereby affecting the desorption/ ionization process. Alternatively, the effect may be in the gas phase with direct neutralization/ionization of ions/molecules by gas phase acid/base chemistry. For example, $\mathrm{D}^{+}$transferred from $[\mathrm{M}+\mathrm{D}]^{+}$or $[\mathrm{M}+$ $\left.\mathrm{ND}_{4}\right]^{+}$to $\mathrm{ND}_{3}$ would neutralize a positive ion, or $\mathrm{H}^{+} / \mathrm{D}^{+}$transferred from a neutral molecule to $\mathrm{ND}_{3}$ would generate an $[\mathrm{M}-\mathrm{H}]^{-}$. Experiments using gaseous deuterium chloride or some other acidic exchange reagent might help to elucidate these effects.

The H/D exchange is effected essentially instantaneously (within one scan, $\sim 6 \mathrm{~s}$ ) which can be important for reducing gas consumption; the nebulizer method uses $\sim 0.7 \mathrm{~L} / \mathrm{min}$ of $\mathrm{ND}_{3}$. Effective exchange (84-97\%) can be observed for most of the molecules tested (Table 1) including exchange of amide hydrogens on the smaller peptides. In particular, for small molecules or those with a small number of labile hydrogens to exchange, it is casy to determine that the exchange has been driven toward completion (with a small amount of incomplete exchange or back ex-
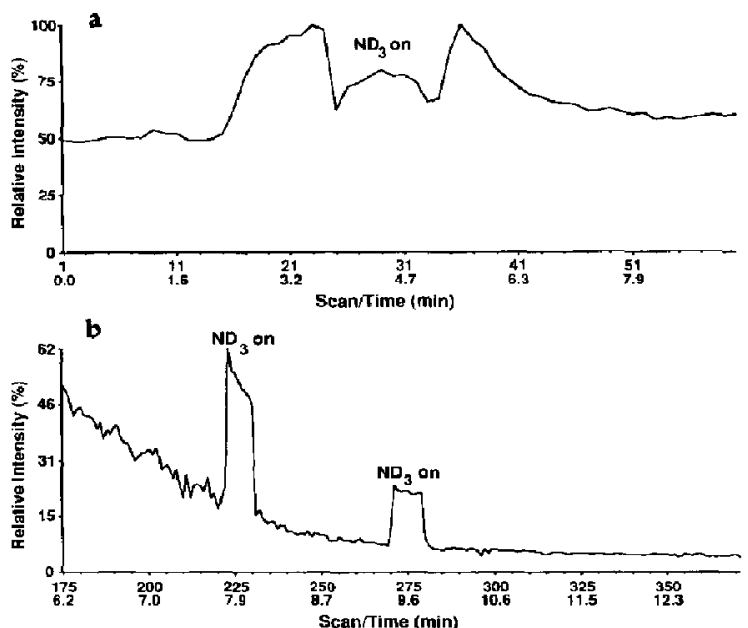

Figure 2. Effect of nebulizer $\mathrm{ND}_{3}$ on total ion current of ascorbic acid: (a) positive ion; (b) negative ion. 
Table 1. Nebulizer and curtain method hydrogen/deuterium exchange results

\begin{tabular}{|c|c|c|c|c|c|c|c|c|}
\hline \multirow[b]{2}{*}{ Compound } & \multirow[b]{2}{*}{$M_{r}$} & \multirow{2}{*}{$\begin{array}{c}\text { Theoretical } \\
\text { No. Exch. } \mathrm{H}^{\mathrm{a}}\end{array}$} & \multicolumn{2}{|c|}{ Nebulizer } & \multicolumn{2}{|c|}{ Curtain } & \multicolumn{2}{|c|}{$\mathrm{DCl} / \mathrm{FAB}$} \\
\hline & & & No. Exch. $\mathrm{H}$ & $\%$ Exch. & No. Exch. H & $\%$ Exch. & No. Exch. H & $\%$ Exch. \\
\hline \multicolumn{9}{|l|}{ Positive ion } \\
\hline Norphenylephrine & 153.1 & 4 & 4 & 84 & 4 & 98 & $4(\mathrm{DCl})$ & 96 \\
\hline Ascorbic acid & 176.0 & 4 & 4 & 92 & 4 & 98 & & \\
\hline Riboflavin & $\mathbf{3 7 6}$ & 5 & 5 & 93 & 5 & 90 & & \\
\hline Met-Leu-Phe & 409.2 & 5 & 5 & 86 & 5 & 75 & $5(\mathrm{FAB})$ & 55 \\
\hline Thr-Tyr-Ser-Lys & 497.2 & 11 & 11 & 92 & 10 & 79 & 11 (FAB) & 74 \\
\hline Renin substrate $(1-14)$ & 1757.9 & 25 & 25 & 87 & 11 & 36 & & \\
\hline Ox. insulin B & $3495.9_{\mathrm{av}}$ & 51 & 45 av & $89^{b, 0}$ & 16 av & $32^{b, c}$ & & \\
\hline Sucrose & 342.1 & $\mathbf{8}$ & 8 & 95 & 8 & 87 & $8(D C l)$ & 93 \\
\hline Raffinose & 504.2 & 11 & 11 & 96 & 11 & 85 & & \\
\hline Stachyose & 666.2 & 14 & 14 & 96 & 14 & 82 & & \\
\hline Maltopentaose & 828.3 & 17 & 17 & 96 & 17 & 73 & & \\
\hline Digitonin & 1228.6 & 17 & 17 & 94 & [17] & 51 & $17(\mathrm{FAB})$ & 76 \\
\hline \multicolumn{9}{|l|}{ Negative ion } \\
\hline Ascorbic acid & 176.0 & 4 & 4 & 91 & 4 & 91 & & \\
\hline Holothurin B & 860.4 & 7 & 7 & 95 & [7] & 37 & & \\
\hline$(d T p)_{7} d T$ & 2370.4 & 17 & 17 & 97 & 17 & 94 & & \\
\hline$(d T p)_{19} d T$ & $6021.9_{\mathrm{av}}$ & 41 & $40 a v^{b, d, f}$ & $96^{b, d}$ & $40 a v^{b, d, f}$ & $96^{b . d}$ & & \\
\hline Ox. insulin B & $3495.9_{a v}$ & 51 & 45 ave.e.t & $87^{\mathrm{b} .}$ & $14 a v^{b, e, t}$ & $24^{\mathrm{b}}$ & & \\
\hline
\end{tabular}

Ali $\mathrm{H}$ attached to hotoroatoms are considered exchangeable. 'Calculated from unresolvod peak centroids. See Exporimental. "Based on

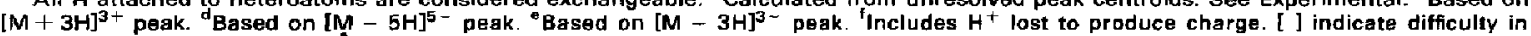
making exact assignment. All $M_{r}$ are monoisotopic values unless indicated as chemical average masses by a subscript av.

change), and the number of exchangeable hydrogens on the molecule can be determined readily by visual inspection of the exchange spectrum compared to the normal spectrum (Figure 3). Nevertheless, at an $\mathrm{ND}_{3}$ flow rate of $\sim 0.7 \mathrm{~L} / \mathrm{min}$, it is possible to reduce the extent of exchange considerably by increasing the flow rate of the protic solvent being electrosprayed (Table 2). At flow rates $\geq 10 \mu \mathrm{L} / \mathrm{min}$, the extent of exchange for the peptide Thr-Tyr-Ser-Lys decreases sufficiently so that the data is no longer readily analyzed by visual inspection; however, we find that $2-3 \mu \mathrm{L} / \mathrm{min}$ flow rates are optimal for normal electrospray operation.

For resolved data, deuterium content (\% exchange) was calculated using a program written in VAX FORTRAN following the method described by McCloskey

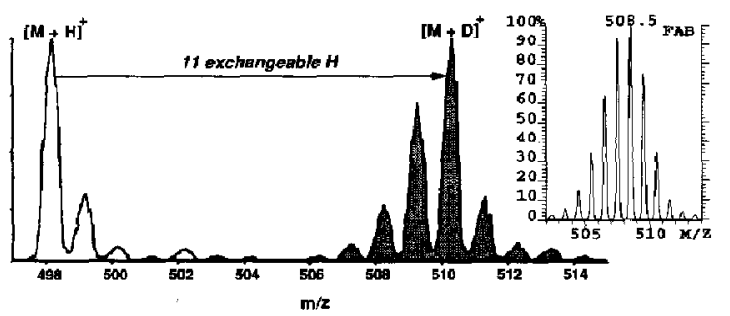

Figure 3. Nebulizer exchange spectrum (shaded) of Thr-TyrSer-Lys showing $[\mathrm{M}+\mathrm{D}]^{+}+11$ exchangeable hydrogens as determined by visual inspection. Exchange efficiency is $92 \%$. Inset: FAB exchange data showing 11 exchangeable hydrogens (determined computationally) at an exchange efficiency of $74 \%$.
[2] based on the original work by Biemann [3]. The results were analyzed directly or plotted as bar graphs to determine the maximum number of exchangeable hydrogens. For unresolved data, deuterium content and number of exchanged hydrogens were calculated based on the shift in peak centroids relative to the expected mass shift for complete exchange, as described by Katta and Chait [16]; the number of exchangeable hydrogens is therefore an average value rather than a maximum. For the purposes of all these calculations, any hydrogen attached to a heteroatom, including amide hydrogens, was considered to be theoretically exchangeable. However, care must be exercised in the interpretation of data from unknowns due to the influence of both the chemical nature [17] and spatial environment, that is, possible tertiary structure [18] on specific potentially exchangeable hydrogens as well as the potential for anomalous exchange.

For molecules like renin substrate-(1-14) with a large number of potentially exchangeable hydrogens and containing amide and guanido hydrogens, the

Table 2. Extent of exchange versus flow rate

\begin{tabular}{cc}
\hline Flow rate, $\mu \mathrm{L} / \mathrm{min}$ & \% Exchange \\
\hline 2 & 93 \\
5 & 85 \\
10 & 81 \\
20 & 76 \\
\hline
\end{tabular}


extent of incomplete exchange or back exchange coupled with the natural isotopic pattern produces a nearly Gaussian distribution of peaks (Figure 4) from which it is nearly impossible to determine the maximum number of exchangeable hydrogens by visual inspection. Rigorous analysis of this kind of data requires removal of the natural isotopic pattern from the exchanged data profile. Replotting of the resulting data for renin substrate-(1-14) (inset, Figure 4) indicates that the actual maximum number of exchanged hydrogens is 25 . The number of exchangeable hydrogens can be verified in a more complicated experiment where an attempt is made to preclude all sources of protons by dissolving the sample in deuterated solvents, using deuterated solvents as the flow injection carrier, purging the atmospheric pressure ionization region with dry $\mathrm{N}_{2}$, and using $\mathrm{ND}_{3}$ as the nebulization gas. Figure $4 \mathrm{~h}$ shows the result of this combined solution and gas phase exchange of renin substrate-(1-14) which can be readily analyzed by visual inspection.

For larger molecules with many exchangeable hydrogens which cannot be mass analyzed as resolved isotopic clusters, a rigorous analysis of the data is not possible. A semirigorous analysis should be feasible following the computational method of Verma et al. [19] by adding an algorithm to generate unresolved peak profiles. Calculation of the exchange level based on the known theoretical number of exchangeable hydrogens is possible using peak centroids, as described
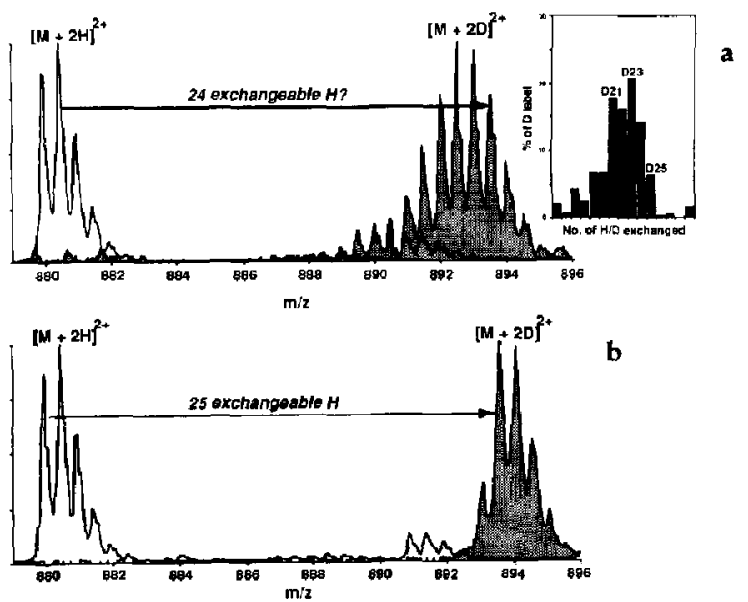

b

Figure 4. (a) Nebulizer exchange spectrum (shaded) of renin substrate tetradecapeptide-(1-14) showing a Gaussian-like distribution. By rigorous computational methods this data indicates that the expected 25 hydrogens have been exchanged at an efficiency of $87 \%$. Inset: Isotopically-corrected barplot showing that the maximal number of hydrogens exchanged is 25 . (b) Combined solution and nebulizer gas phase exchange spectrum (shaded) of renin substrate (1-11). Sample was dissolved in 2:3:3 $\mathrm{d}_{4}$-acetic acid $/ \mathrm{d}_{4}$-methanol/ $\mathrm{d}_{2}$-water and flow injected into 1:1 $\mathrm{d}_{4}$-methanol $/ \mathrm{d}_{2}$-water flowing at $3 \mu \mathrm{L} / \mathrm{min}$; nebulization was by $\mathrm{ND}_{3}$ at $\sim 0.7 \mathrm{~L} / \mathrm{min}$ into an atmospheric pressure ionization region purged with dry $\mathrm{N}_{2}$ in the Experimental section. These values can then be used to back-calculate an average number of exchanged hydrogens observed, but this process would not be useful for determining the maximum number of exchangeable hydrogens in unknowns. In spite of such problems with data analysis, even these larger molecules with many exchangeable hydrogens in various chemical environments yielded reasonable levels of exchange ( $87-96 \%$ ) using the nebulizer method.

\section{Curtain Exchange}

$\mathrm{H} / \mathrm{D}$ exchange can also be accomplished by introducing $\mathrm{ND}_{3}$ as a portion $(1-10 \%)$ of the curtain gas. It was thought that effecting $\mathrm{H} / \mathrm{D}$ exchange at the atmosphere/vacuum interface would be a way to reduce possible back exchange and to decouple the exchange reaction from any effect the $\mathrm{ND}_{3}$ gas might have on the desorption/ionization process. Introduction of $\mathrm{ND}_{3}$ in this region can cause significant clustering $\left[\mathrm{ND}_{4}^{+}+\right.$ $\left.\mathrm{n}\left(\mathrm{ND}_{3}\right)\right]$ and adduction $\left[(\mathrm{M}+\mathrm{D})^{+}+\mathrm{n}\left(\mathrm{ND}_{3}\right)\right]$ to be observed. Increasing the declustering potential (regulated by the oriface potential, OR, on the Sciex API-III) helps to eliminate the clustering and reduces the adduction (Figure 5). If the declustering potential is increased too much, fragmentation may also be induced as evidenced by the increasing intensity of the water loss $\left(-\mathrm{D}_{2} \mathrm{O}\right)$ peak in Figure 5. Increasing the declustering potential also seems to help drive the exchange process toward completion through more energetic collisions.
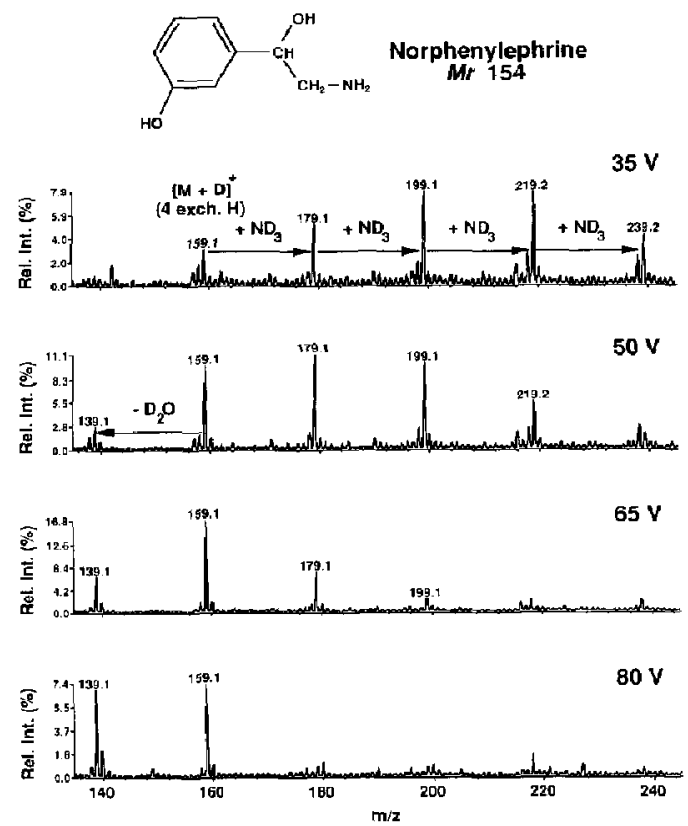

Figure 5. Effect of increased declustering potential (OR - R0) in curtain exchange experiment on $\mathrm{ND}_{3}$ adduction to and fragmentation of norphenylephrine. 
Increasing the curtain $\mathrm{ND}_{3}$ concentration can also be used to try to drive the exchange process toward completion for the more refractory molecules (Figure 6). However, clustering and adduction will increase; therefore, the declustering potential must be increased simultaneously to reduce these effects, with the consequence that the exchange is driven forward by more energetic collisions.

Curtain $\mathrm{H} / \mathrm{D}$ exchange is effective $(90-98 \%$ exchange) for small molecules with relatively few active or labile hydrogens. The larger molecules were more difficult to exchange effectively (37-87\% exchange) using the curtain method, as were the peptides (24-79\%) which contain amide hydrogens which are less active. Notable exceptions to this are the two nucleotides (17 and 41 exchangeable hydrogens, respectively) which were both exchanged nearly completely $(94-96 \%)$ in the negative ion mode, for example, see Figure 7. In general, the lower levels of exchange obtained by the curtain method made it difficult to determine a maximum number of exchangeable hydrogens by visual comparison of the exchange versus normal spertra. Rigornus computational methnds must be used to determine the actual number of exchanged hydrogens.

Curtain $H / D$ exchange suffers from residual gas effects, particularly when the plenum is configured
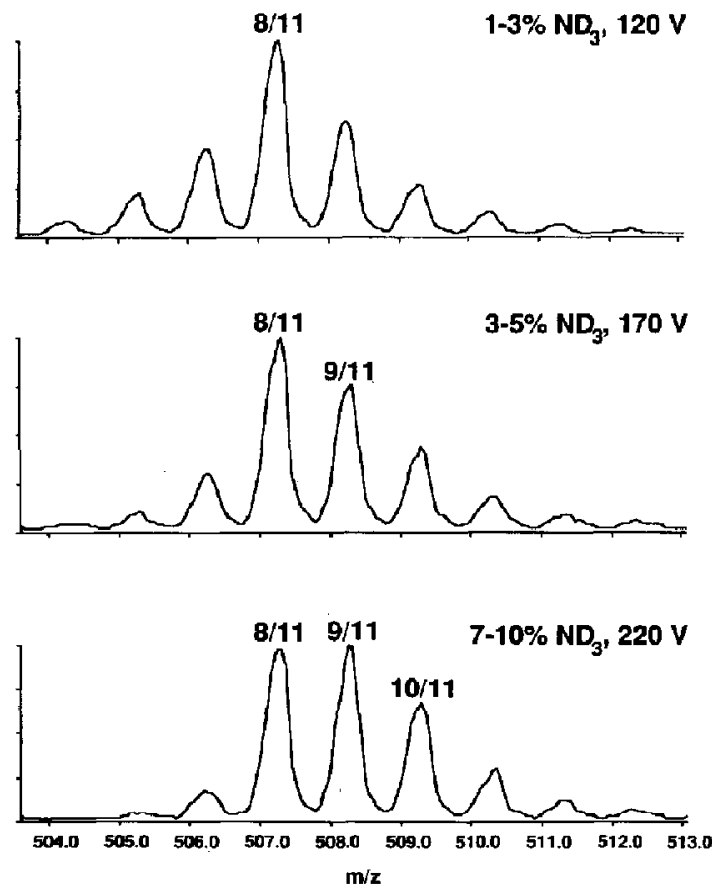

Figure 6. Effect of increased $\mathrm{ND}_{3}$ concentration and declustering potential $(O R-R 0)$ in curtain exchange experiment on extent of exchange for Thr-Tyr-Ser-Lys. As both the $\mathrm{ND}_{3}$ concentration and declustering potential are increased, the fraction of exchangeable hydrogens which have been exchanged increases.
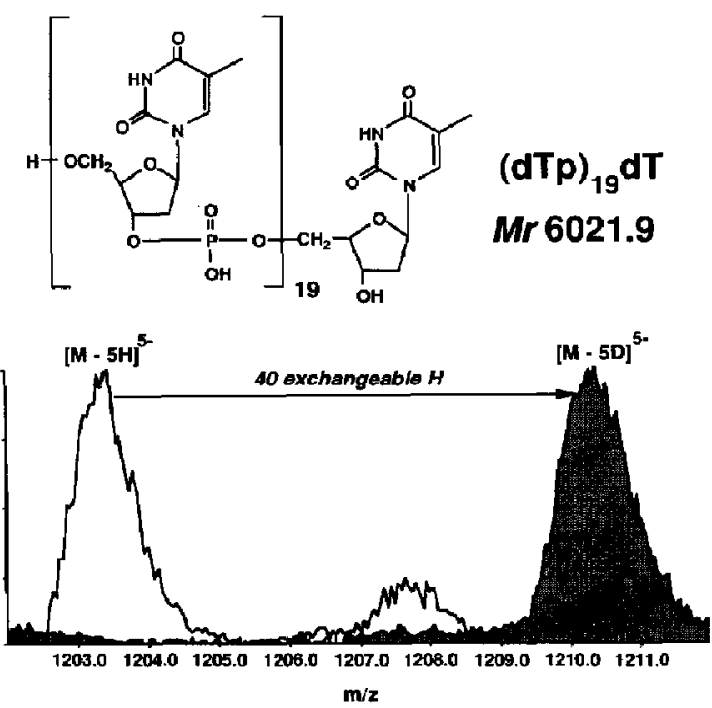

Figure 7. Example of effective curtain exchange (shaded) on a polynucleotide, (dTp) ${ }_{19} \mathrm{dT}$, of $M_{\mathrm{r}} 6021.9_{\mathrm{z}}$ which was analyzed in the negative ion mode. The data show an average of 40 hydrogens of 41 possible have been exchanged with an exchange efficiency of $96 \%$ based on a shift from $m / z 1203.4$ to $m / z 1210.4$ (versus $m / 21210.6$ expected for complete exchange of $41 \mathrm{H}$ ). A maximum number of exchangeable hydrogens is not calculable because the isotopic cluster at this mass is unresolved. Similar exchange was observed in the nebulizer data (Table 1).

with a Teflon gasket/Viton O-ring seal rather than the Macor/indium configuration used in most of the experiments here. Residual $\mathrm{ND}_{3}$ can be observed to exert its effects for several hours after the gas has been turned off and usually requires a recycle of the cryopumping system to be completely removed. Nevertheless, the reduced gas consumption (1-10\% versus nebulizer exchange experiments) makes this method suitable for cases where prolonged production of exchanged species are required such as for tandem mass spectrometry or LC./MS experiments. Other ways of introducing the $\mathrm{ND}_{3}$ to the orifice more directly, for example, via a capillary positioned directly behind the sampling orifice, may help to reduce the recovery time. The addition of $\mathrm{ND}_{3}$ to the $\mathrm{N}_{2}$ curtain gas in the proportions used has no adverse effect on the vacuum in the instrument; in fact, because $\mathrm{ND}_{3}$ has a freezing point of $-74{ }^{\circ} \mathrm{C}$ versus $-210{ }^{\circ} \mathrm{C}$ for $\mathrm{N}_{2}$ and is more viscous, the vacuum improves slightly at higher concentrations of $\mathrm{ND}_{3}$.

\section{Glycosides}

One potential problem in analyzing unknowns first became apparent in the analysis of the sugars by the nebulizer exchange method. Since sugars ionize/desorb well in the cationization mode, we chose to run these experiments using relatively volatile ammonium acetate as the source of cation in the sample solutions. 
However, rather than observing a maximally exchanged isotope pattern which matched the isotope pattern of the unexchanged sample, the $P+1$ isotope peak was unexpectedly enhanced even though the overall profile is quite clean and strong (Figure 8). In other exchange methods, such as $\mathrm{ND}_{3}$-desorptive chemical ionization, enhanced $P+1$ isotope peaks can be indicative of partial anomalous exchange (see below) of hydrogen not bonded to heteroatoms [20,21] or might suggest incomplete exchange due to hydrogen bonding [22]. However, in this case the elevation in the $P+1$ peak was found to be a result of the contribution of adventitious $[\mathrm{M}+\mathrm{Na}]^{+}$to the $[\mathrm{M}+$ $\left.\mathrm{ND}_{4}\right]^{+}$pattern $(+23 \mathrm{Da}$ versus $+22 \mathrm{Da}$ ). The contribution from this peak is not necessarily proportional to the relative intensity of the unexchanged $[\mathrm{M}+\mathrm{Na}]^{+}$ versus $\left[\mathrm{M}+\mathrm{NH}_{4}\right)^{+}$which could lead to problems in interpretation of the exchange data. Such problems can be avoided by the addition of low $\mathrm{mM}$ concentrations of alkali salts instead of ammonium salts, as described below.

As in the nebulizer method, the tendency of sugars to form various cationized species was evident in the curtain exchange method. As indicated above, this could cause problems in trying to assign the maximum number of exchangeable hydrogens in unknown glyco-
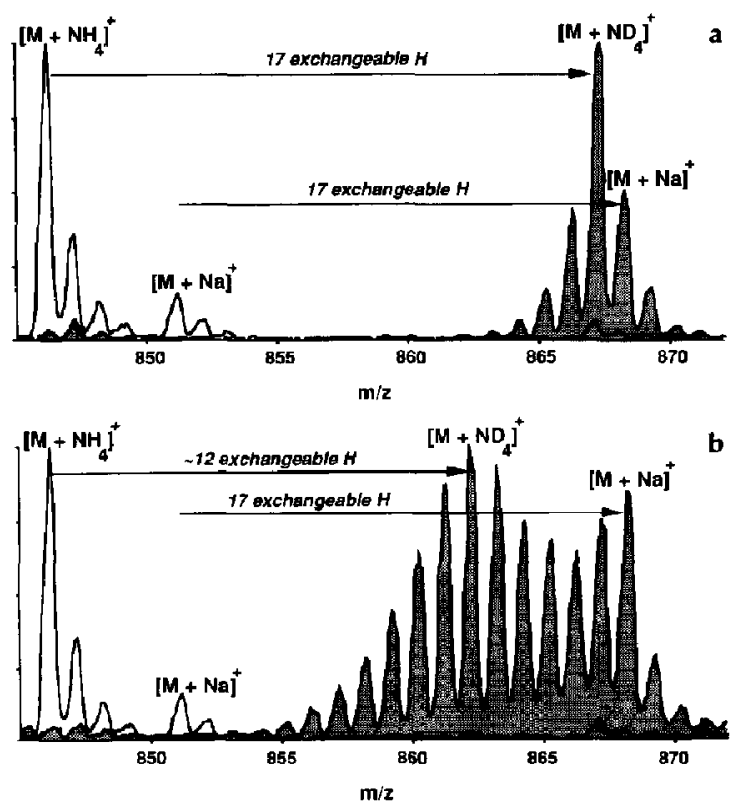

Figure 8. Example of (a) nebulizer and (b) curtain exchange spectra (shaded) for maltopentaose. The nebulizer data (a) shows clean, nearly complete ( $96 \%$ ) exchange of 17 exchangeable hydrogens with an elevated $P+1$ isotope as a result of the contribution of $[\mathrm{M}+\mathrm{Na}]^{+}$. The curtain data (b) shows a bimodal distribution presurned to be a result of the greater stability of the $[\mathrm{M}+\mathrm{Na}]^{+}$relative to $\left[\mathrm{M}+\mathrm{ND}_{4}\right]^{+}$under the declustering conditions used $(\mathrm{OR}-\mathrm{RO}=170 \mathrm{~V})$. sides which produce both $[\mathrm{M}+\mathrm{Na}]^{+}$and $\left(\mathrm{M}+\mathrm{ND}_{4}\right)^{+}$ ions. However, one can take advantage of the presence of a more stable $[\mathrm{M}+\mathrm{Na}]^{+}$ion [23]. In order to try to drive the curtain exchange reaction to completion on molecules with more than a few exchangeable hydrogens, the declustering potential was increased in order to provide more energy for the collisional exchange process. The resulting exchange data show a distinct bimodal distribution that becomes more pronounced as the molecule size and number of exchangeable hydrogens increases (Figure 8). While the increased declustering potential may be of assistance in driving the exchange towards completion, processes such as collision-induced fragmentation, scattering, and probably neutralization (through dissociation of $\mathrm{ND}_{4}^{+}$from the pseudomolecular ion or through proton transfer from the pseudomolecular ion to neutral $\mathrm{ND}_{3}$ ) are competing with the exchange reaction. However, the $[\mathrm{M}+\mathrm{Na}]^{+}$species appears to be more stable towards these competing processes. Therefore, in lieu of rigorously desalting samples, one should consider using sodium salts at $0.5-5 \mathrm{mM}$ concentration for ionization of unknown glyonsides and other compounds prone to cationization, Together with an elevated declustering potential to reduce interfering $[\mathrm{M}+\mathrm{H}]^{+}$and $[\mathrm{M}+$ $\left.\mathrm{NH}_{4}\right]^{+}$, this technique should produce an unambiguous, stable, alkali metal-cationized species for analysis.

\section{Anomalous Exchange}

Exchange results are considered to be anomalous if the number of exchangeable hydrogens determined does not reflect the number expected for experiments that appear to have been driven toward completion. Normally this is due to exchange of hydrogen attached to carbon that has been activated by nearby substituents $[20,21]$ and results in excess exchange. However, certain $\mathrm{ND}_{3}-\mathrm{DCl}$ conditions can result in cleanly underexchanged spectra in cases where hydrogen bonding is involved, such as, 1,4,9,10-tetrahydroxyanthracene [22]. Several compounds were examined by both nebulizer and curtain exchange methods for the possibility of anomalous deuterium exchange. The preliminary results in Table 3 show that under electrospray gas-phase exchange conditions only the most activated compounds show anomalous exchange. For example, each of the three carbon-bound hydrogens attached to the aromatic ring in phloroglucinol is activated by each of the three phenolic oxygens, and this molecule shows a predominant peak for six exchangeable hydrogens in both the nebulizer and curtain exchange mass spectra. Dibenzoylmethane also shows what might be considered anomalous exchange of one hydrogen. This anomalous exchange is likely a result of keto-enol tautomerism, and the fact that two anomalous exchanges are not observed suggests that the compound is locked into the enol form where the entire system is in conjugation. Neither of the other two compounds which showed excess exchange by $\mathrm{ND}_{3}$-DCI (Table 3 ) 
Table 3. Anomalous exchange results

\begin{tabular}{|c|c|c|c|c|c|}
\hline \multirow[b]{2}{*}{ Compound } & \multirow[b]{2}{*}{$M_{r}$} & \multirow{2}{*}{$\begin{array}{l}\text { Theor. } \\
\text { No. Exch. } H^{\mathrm{a}}\end{array}$} & \multicolumn{3}{|c|}{ Number of Exchanged Hydrogens } \\
\hline & & & Nebulizer & Curtain $^{\text {b }}$ & $\mathrm{DCl}^{\mathrm{c}}$ \\
\hline \multicolumn{6}{|l|}{ Positive ion } \\
\hline 4-Aminoresorcinol & 125 & 4 & 4 & 4 & $4 / 5 / 6(\mathrm{DCl})$ \\
\hline Phloroglucinol & 126 & 3 & 6 & 6 & $6(\mathrm{DCl})$ \\
\hline Acetoacetanilide & 177 & 1 & 1 & 1 & $3(\mathrm{DCl})$ \\
\hline Dibenzoylmethane & 224 & $\mathbf{0}$ & 1 & 1 & $2(\mathrm{DCl})$ \\
\hline
\end{tabular}

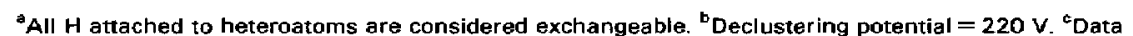
from Ref. [19]

showed any sign of anomalous exchange under identical nebulizer or curtain exchange conditions.

Attempts to investigate anomalous exchange in several other compounds were thwarted for several reasons. Many of the compounds previously analyzed for anomalous exchange $[20,21,22]$ are relatively nonpolar and not very amenable to ESIMS, resulting in little or no molecular ion current. Even when a sufficiently strong ion current can be obtained in the normal spectrum, for example, through use of high concentrations of analyte, the analyte response in the exchange spectrum can be completely quenched via the mechanisms discussed above. Hence, we were unable to obtain data of sufficient quality to investigate compounds such as $1,3,9,10$-tetrahydroxyanthracene or 2,4,6-trihydroxybenzaldehyde. We plan to investigate this further using an acidic exchange reagent such as gaseous deuterium chloride to overcome these problems. The preliminary results observed here indicate that further investigation of anomalous exchange is warranted with careful selection of compounds that are amenable to ESIMS analysis.

\section{General}

ESI gas phase $H / D$ exchange compares favorably with our experiences with $\mathrm{DCI}$ and $\mathrm{FAB} \mathrm{H} / \mathrm{D}$ exchange results (Table 1). Both of these other methods work well for small molecules or molecules with few exchangeable hydrogens. $\mathrm{ND}_{3}-\mathrm{DCI}$ seems to be limited mainly by the type and size of molecules that are amenable to DCI; however, it can be a much more vigorous process, exchanging hydrogens on carbons which are activated by other substituents $[20,21,22]$. FAB exchange experiments seem to be limited by more basic problems including slow exchange, back exchange, reduction processes, radiation damage related processes, etc. ESI nebulizer $H / D$ exchange worked efficiently (>90\% exchange) for most of the compounds studied and allowed accurate determination of the number of exchangeable hydrogens $(\leq 25)$ on all of the compounds studied below $M_{r}$ 3000; it is not clear whether efficient nebulizer exchange is limited by mass (and consequent tertiary structure), by total number of theoretically exchangeable hydrogens, by the chemical nature of potentially exchangeable hydrogens, or by some combination thereof. The curtain method was experimentally more difficult and did not work with the same efficiency as nebulizer exchange. Nevertheless, the number of exchangeable hydrogens could be accurately determined with the curtain exchange method for $>50 \%$ of the compounds studied ( $>70 \%$ of those below $M_{r} 3000$ ), using computational analysis as necessary. ESI gas phase $\mathrm{H} / \mathrm{D}$ exchange seems to have few restrictions relative to compound type, solvent requirements (at typical $2 \mu \mathrm{L} / \mathrm{min}$ flow rates), or ion polarity. Anomalous exchange problems are reduced relative to DCI but are still of concern.

Much of the data obtained here was from experiments using $5 \mathrm{mM} \mathrm{NH}{ }_{4} \mathrm{OAc}$ solutions. This has generally been a useful means for obtaining data by promoting the formation of $\left[\mathrm{M}+\mathrm{NH}_{4}\right]^{+}$ions which are either analyzed directly or dissociate to $\left[\mathrm{M}+\mathrm{H}^{+}\right.$prior to analysis. However, in cases where the compounds have a propensity to form other cationized pseudomolecular ions (in addition to $[\mathrm{M}+\mathbf{H}]^{+}$or $[\mathrm{M}+$ $\mathrm{NH}_{4} \mathrm{l}^{+}$) in the presence of adventitious salts, such as the glycosides analyzed in this study, it might be more useful to force the analyte to a single pseudomolecular ion such as the $[\mathrm{M}+\mathrm{Na}]^{+}$through the use of an appropriate salt. This would serve several purposes: (1) to force the majority of the pseudomolecular ion current into a single species, reducing the complexity of the spectrum and potentially increasing sensitivity and (2) to create a more stable species that would withstand the high declustering potentials used to drive the curtain exchange to completion, hopefully eliminating bimodal distributions. Preliminary experiments using $\mathrm{NaOAc}$ have demonstrated that a single species can be formed, that is, a bimodal distribution is not observed even at high declustering potentials. However, even with high declustering potentials, the exchange is not as complete as the $\mathrm{NH}_{4} \mathrm{OAC} /$ nebulizer data (Figure 8a). Additional experiments with potassium cationized molecules are warranted [23].

\section{Conclusions}

ESIMS gas phase $H / D$ exchange is a quick and effective way to determine the number of exchangeable hydrogens on small molecules, similar to DCI, and is 
capable of exchanging many of the active hydrogens on larger molecules. Rapid switching between air and $\mathrm{ND}_{3}$ in the nebulizer method provides for both normal and exchange data from a single loading of sample. For compounds containing more than a few active hydrogens which are often not amenable to DCI, ESI gas phase exchange via the nebulizer is, in practice, simpler and more efficient than FAB H/D exchange. The ESIMS exchange methods show less anomalous exchange of hydrogen not attached to heteroatoms. Improvements to the curtain exchange experiment to render the exchange process more effective, and combination of one or both of the gas phase experiments with an optimized solution exchange technique, may provide a universal method for complete and effective exchange of molecules of all types and sizes. Because the nebulizer exchange method may be switched on and off rapidly and, at low flow rates, is not restricted by special solvent requirements, it has potential for use during LC, MS analyses, which should be explored.

\section{Acknowledgment}

The authors thank Professor R. Kaufmann for a preprint, B. Poehland for providing the holothurin B sample, and L. Killmer for providing some of the samples used to investigate anomalous exchange.

\section{References}

1. Budzikiewicz, H.; Djerassi, C.; Williams, D. H. Structure Elucidation of Natural Products by Mass Spectrometry; HoldenDay: San Francisco, 1964; Vol. 1, Chap. 2.

2. McCloskey, J. A. In Methods in Enzymology; McCloskey, J. A., Ed.; Academic: New York, 1990; Vol. 193, pp. 329-338.

3. Biemann, K. Mass Spectrometry: Organic Chemical Applications; McGraw-Hill: New York, 1962; Chapter 5.
4. Hunt, D. F,; McEwen, C. N.; Upham, R. A. Anal. Chem. 1972, $44,1292-1294$.

5. Setli, S. K.; Smith, D. L.; McCloskey, J. A. Biochent. Biophys. Res. Contmun. 1983, 112, 126-131.

6. Edmonds, C. G.; Pomerantz, S. C.; Hsu, F. F.; MeCloskey, J. A. Anal. Chem. 1988, 60, 2314-2317.

7. Siegel, M. M. Anal. Chem. 1988, 60, 2090-2095.

8. Little. J. L.; Cook, L. A. Proceedings of the 40th Annual ASMS Conference on Mass Spectrometry and Allied Topics; Washington, DC, May 31-June 5, 1992; pp. 1462-1463.

9. Spengler, B.; Lützenkirchen, F.; Kaufmann, R. Org. Mass Spectrom. 1994, 19, in press.

10. McCloskey, J. A. In Methods in Enzymology; Lowenstein, J., Ed.; Academic: New York, 1969; Vol. 14, pp. 382-450.

11. Henion, J. D. J. Chromatogr. Sci. 1981, 19, 57-64.

12. Katta, V.j Chait, B. T. Rapid Commun. Mass Spectrom. 1991, 5 , 214-217.

13. Suckau, D.; Shi, Y,; Beu, S. C.; Senko, M. W.; Quinn, J. P.; Wampler, F. M., III; McLafferty, F. W. Proc. Natl. Acad. Sci. USA 1993, 90, 790-793.

14. Ogorzalek, R. R.; Loo, J. A.; Smith, R. D. Proceedings of the 40th Annual ASMS Conference on Mass Spectrometry and Allied Topics; Washington, DC, May 31-June 5, 1992; pp. 645-646.

15. Kitagawa, I.; Nishino, T.; Matsuno, T.; Akutsu, H.; Kyogoku. Y. Tetrakedron Lett. 1978, 985-988.

16. Katta, V.; Chait, B. T. J. Am. Chem. Soc. 1993, 115, 6317-6321.

17. Thévenon-Emeric, G.; Kozlowski, J.; Zhange, Z.; Smith, D. L. Anal. Chem. 1992, 64, 2456-2458.

18. Miraker, A.; Robinson, C. V.; Radford, S. E; Aplin, R. T; Dobson, C. M. Science 1993, 262, 896-900.

19. Verma, S; Pomerantz, S. C.; Sethi, S. K.; McCloskey, J. A. Anal. Chem. 1986, 58, 2898-2902.

20. Hunt, D. F.; Sethi, S. K. J. Am. Chem. Soc. 1980, 102, 6953-6963.

21. Martinsen, D. P.; Buttrill, S. E. Jr. Org. Mass Spectrom. 1976, 11, 762-772.

22. Killmer, L. B. Proceedings of the 36th Antual ASMS Conference on Mass Spectrometry and Allied Topics; San Francisco, CA June 5-10, 1988; pp. 665-666.

23. Laine, R. A.; Yoon, E.; Mahier. T. J.: Abbas, S.; de Lappe, B.; Jain, R.; Matta, K. Biol. Mass Spectrom. 1991, 20, 505-514. 